\title{
Fast and slow artificial diurnal rhythms (light-darkness-light) and the rate of progression of retinal degeneration in dystrophic RCS rats. An electroretinographic study
}

\author{
KLAS-OLAVSKOOG \\ From the Department of Ophthalmology, University hospital, S-581 85 Linköping, Sweden
}

\begin{abstract}
SUMMARY The RCS rat strain is characterized by a hereditary progressive degeneration of retina and pigment epithelium. The possible influence of varying artificial diurnal rhythms on the rate of progression of the degeneration was investigated with electroretinography (ERG). Light intensity of the 'day'-periods and the total light exposure were constant in two groups of RCS rats subjected to $2 \mathrm{~h}$ light $/ 2 \mathrm{~h}$ darkness and to $24 \mathrm{~h}$ light $/ 24 \mathrm{~h}$ darkness periods respectively. No difference in the rate of degeneration as mirrored by the ERG was seen between the two groups. The ERGs were unrecordable after 7-8 weeks, and the experiments started at birth. No changes in the ERG of controls, genetically identical with the RCS strain except for the retinal dystrophy gene, were seen when they were subjected to the two diurnal rhythms. The results lessen the probability that careful long-term patching of an eye in patients with retinitis pigmentosa or other related hereditary degenerative diseases (in order to diminish the influence of diurnal illumination changes leading to shedding of receptor outer segments) will halt or modify the progression of the disease in man.
\end{abstract}

Rodent diseases causing photoreceptor degeneration were described by Keeler' in mice and by Bourne $e t$ $a .^{2}$ in RCS (Royal College of Surgeons) rats. The degeneration in the rat shares with certain human retinal degenerations the features of heritability, destruction of photoreceptor cells, migration of pigment epithelial cells into the neural retina in the late stages of the disease, and other similar end-stage pathological features. ${ }^{3}$ The RCS rat is currently being studied as one of several possible animal models for human retinitis pigmentosa at several research centres. These animals are characterised by a disorder in the pigment epithelium surrounding the neuroretina: a lack of phagocytosis of shed rod outer segment discs leads to the accumulation of debris between the pigment epithelium and the retina. This causes a secondary destruction of the neuroretina. ${ }^{+}$ The pathogenesis of the group of human eye disorders called retinitis pigmentosa is probably manifold, but a defect in phagocytosis of the pigment epithelium might exist in some subgroups of retinitis pigmentosa or related diseases.

Correspondence to Dr Klas-Olov Skoog
The effects of various ambient light conditions on the rate of progression of the retinal degeneration in RCS rats have been studied by a number of researchers. ${ }^{5-7}$ Strong light precipitates an early onset of the degeneration and a faster decline in retinal functions. These and similar results led Berson ${ }^{\star}$ and others to try to halt or slow down the rate of progression of human retinitis pigmentosa by patching one eye and thus greatly reducing the intensity of the light reaching the eye. However, Berson" recently reported no evidence to substantiate that light deprivation with sun glasses or opaque contact lenses will modify the rate of progression of retinitis pigmentosa. The reason of the failure might be that the protected eyes were not totally occluded but easily perceived the diurnal changes in light intensity caused by day and night. The shedding of rod outer segments which must then be phagocytised by the pigment epithelium is normally, at least in certain animals, precipitated by the daybreak in a diurnal rhythm, even if a certain rhythm is preserved in total darkness.

A slowing of the degeneration by rearing the dystropic rats in total darkness was observed by Dowling and Sidman. In that and similar studies 


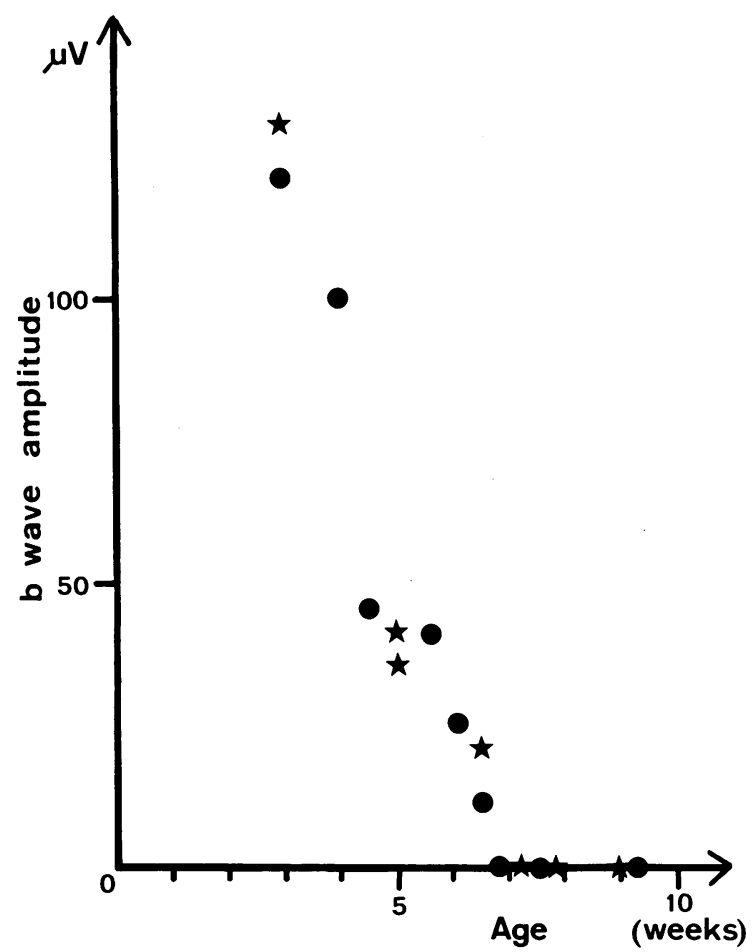

Fig. 1 The development of the retinal degeneration of young $R C S$ rats as mirrored by the disappearance of the $b$ wave of the ERG. Each dot represents an animal raised in an artificial diurnal rhythm of 2 h darkness $/ 2$ h light. Each star represents an animal reared in an artificial cycle of $24 \mathrm{~h}$ darkness/24h light.

both the total amount of light exposure and at the same time the frequency of light changes were varied in different animal groups. The author considered it of interest to study further the effects of light/ darkness rhythms on the rate of decline of retinal function as measured by the electroretinogram (ERG) and to seek to isolate the effects of the diurnal rhythm itself. If the light intensity of the artificial day periods and the total time of light exposure for the lifetime of the animals are kept constant in different series of experiments but the frequencies of the artificial day/night cycles are different in each series, the possible influence on the disease of the light-dark -light changes themselves can be tested.

The present study concerns the effects of artificially hastened and slowed diurnal light rhythms on the rate of degeneration of the retina in RCS rats as mirrored by the ERG.

\section{Materials and methods}

The $20 \mathrm{RCS}$ rats of this study were pink-eyed beigehooded animals. Similarly pigmented animals, congenic with the RCS rats except for the retinal degeneration gene, served as controls. Cannibalism and neglect of the young rats by their mothers lead to the loss of several litters of animals. Some rats (RCS and controls) were housed from birth in a separate room with a 2 hours light (200 lux from an ordinary light bulb) $/ 2$ hours darkness cycle monitored by an electric timer. Others were exposed to a 24 hours light/24 hours darkness cycle.

Before ERG recordings were made the rats were dark adapted for $2 \mathrm{~h}$. They were anaesthetised with sodium pentobarbital $(40 \mathrm{mg} / \mathrm{kg}$ body weight intraperitoneally). Their pupils were dilated with atropine given topically, and the eyelids were held apart with fine sutures. Sometimes a canthotomy had to be performed to eliminate contact between the recording electrode and the lids. The preparation of the animals (the application of a recording platinium electrode on the cornea of one eye, a reference platina electrode on one ear, and a ground electrode on the back of the animal etc.) was carried out in a very dim red light before dark adaptation. Stimulus intensity about 60 lux and stimulus duration $40 \mathrm{~ms}$ and sometimes $1 \mathrm{~s}$ were provided through a halogen lamp, neutral filters, an electromagnetic shutter, and fibre optics. ERGs were recorded from animals aged between 3 and 10 weeks. A few controls were followed up for four months. Each animal was used in only one recording and subsequently killed. The b wave was measured from the trough of the a wave to the peak of the $b$ wave.

\section{Results}

A normal ERG with prominent $\mathrm{a}, \mathrm{b}$, and $\mathrm{c}$ waves was found in control animals. When reared in ordinary flourescent light (400 lux) ( $12 \mathrm{~h}$ light $/ 12 \mathrm{~h}$ darkness) a light-induced degeneration occurred in the control rats with a very low ERG response after about four months.

Control rats subject to 200 lux light from an ordinary light bulb did not show a decreased ERG after two months whether reared under $2 \mathrm{~h}$ light $/ 2 \mathrm{~h}$ darkness or $24 \mathrm{~h}$ light $/ 24 \mathrm{~h}$ darkness cycles.

$\mathrm{RCS}$ rats subjected to $2 \mathrm{~h}$ light $/ 2 \mathrm{~h}$ darkness or $24 \mathrm{~h}$ light $/ 24 \mathrm{~h}$ darkness conditions showed a progressive retinal degeneration leading to an unrecordable ERG after between 7 and 8 weeks of age. Only a and b waves were recorded because of some difficulty in obtaining reliable recordings of the non-existent or very low $\mathrm{c}$ waves of the young RCS rats living in the above light conditions. The development of the retinal damage of $16 \mathrm{RCS}$ rats provoked by the two diurnal rhythms as mirrored by the $b$ waves of the ERG is seen in Fig. 1. No substantial difference between the groups in the rate of progression of this 
illness could be demonstrated. Before the exact time of disappearance of the ERG was known four animals not shown in Fig. 1 were studied after eight weeks of age. They had no recordable ERG response.

\section{Discussion}

One must be very careful when comparing the findings of the present study with the results of others, since the RCS strains may differ among laboratories. Considerable differences in light sensitivity between RCS rats of varying degrees of pigmentation were recently reported by LaVail."' Strongly pigmented RCS rats showed less difference in disease progression than lightly pigmented RCS animals (such as our pink-eyed variety) when reared in continuous darkness compared with a life under ordinary diurnal light changes. The $b$ wave of our rats never reached the maximum value $(600 \mu \mathrm{V})$ reported in the study of Kaitz and Auerbach. ${ }^{7}$ The explanation might be slightly different RCS strains or different experimental and laboratory conditions. The important point is that there occurred a fast predictable degeneration in our RCS rats with an unrecordable ERG after 7-8 weeks and that laboratory and experimental conditions were identical for all rats (all from the same strain) except for the difference in frequency between the artificial diurnal rhythms.

Cannibalism and neglect of the young rats by their mothers have slowed the progress of the experiments at times. To conserve a necessary number of rats (only one rat was used in each recording) it was necessary to investigate some litters only in the last weeks before the ERG was extinct. Such erratic behaviour in these strains of rats sometimes happens, but the cause is unknown."'

A recent report" shows that light deprivation, which slows the disease in pink-eyed rats, has no protecting effect on dark pigmented RCS rats. This leads to the conclusion that the suggested therapy of light deprivation for retinitis pigmentosa patients proposed by Berson ${ }^{8}$ must be viewed with less optimism. The suggestion was based on the assumption that human retinitis pigmentosa might be caused by a similar defect in pigment epithelial phagocytic capability. However, this theory is not at present considered to be the most likely. Instead a defect in cyclic guanosine monophosphate (GMP) metabolism is now considered to be more probable. On the other hand a large number of various hereditary diseases affect the retina, and it cannot be excluded that some of them are related to defective phagocytosis.

It is well known that profound changes occur in the eye in response to lasting changes in illumination. Rod outer segments are shed at daybreak, at least in certain animals. The retina and pigment epithelium react with long-lasting 2-hour oscillations in the standing potential of the eye in response to changes in the level of adaptation. It therefore did not seem unlikely that artificially hastened diurnal rhythms would constitute an extra stress factor to the diseased RCS rats with their known defect in the phagocytosis of rod outer segments (see above). However, the present study indicates that the frequency of diurnal rhythms does not seem to influence the progression of the disease in pink-eyed RCS rats. It further lessens the hope that continuous efficient patching of one eye of patients with retinitis pigmentosa or other hereditary degenerative fundal diseases, so that less diurnal illumination changes are perceived, will retard the disease.

This study was supported by grants from the Swedish Medical Research Council (project No. 04X-05929). Breeding pairs of the RCS strain and their congenic controls were most kindly supplied free of charge by Professor M M LaVail, Department of Anatomy, University of California, San Francisco, USA.

\section{References}

1 Keeler CE. The inheritance of a retinal abnormality in white mice. Proc Natl Acad Sci USA 1924; 10: 329-33.

2 Bourne MC, Campbell DA, Tansley K. Hereditary degeneration of the rat retina. Br J Ophthalmol 1938; 22: 613-23.

3 LaVail MM. (1979): The retinal pigment epithelium in mice and rats with inherited retinal degeneration. In: Zinn KM, Marmor MF, eds. The retinal pigment epithelium. Cambridge, Mass: Harvard University Press, 357-80.

4 Herron WL, Riegel BW, Myers, OE, Rubin ML. Retinal dystrophy in the rat - a pigment epithelial disease. Invest Ophthalmol Visual Sci 1969; 8: 595-604.

5 Dowling JE, Sidman RL. Inherited retinal dystrophy in the rat. $J$ Cell Biol 1962; 14: 73-109.

6 LaVail MM, Battelle B-A. Influence of eye pigmentation and light deprivation on inherited retinal dystrophy in the rat. Exp Eye Res 1975; 21: 167-92.

7 Kaitz M, Auerbach E. Retinal degeneration in RCS rats raised under ambient light levels. Vision Res 1979; 19: 79-81.

8 Berson EL. Light deprivation for early retinitis pigmentosa. A hypothesis. Arch Ophthalmol 1971; 85: 521-9.

9 Berson EL. Light deprivation and retinitis pigmentosa. Vision Res 1980; 20: 1179-84.

10 LaVail MM. Interaction of environmental light and eye pigmentation with retinal degeneration. Vision Res 1980; 20: 1173-7. 